\title{
Effectiveness and tolerability of transdermal rivastigmine in the treatment of Alzheimer's disease in daily practice
}

This article was published in the following Dove Press journal:

Neuropsychiatric Disease and Treatment

2 April 2012

Number of times this article has been viewed

\author{
Johannes Seibert ${ }^{\prime}$ \\ Ferenc Tracik ${ }^{2,3}$ \\ Konstantin Articus ${ }^{2}$ \\ Stefan Spittler ${ }^{4}$ \\ 'Outpatient Clinic, Heidelberg, \\ Germany; ${ }^{2}$ Novartis Pharma, \\ Nürnberg, Germany; ${ }^{3}$ Department of \\ Neurology, Heinrich-Heine University, \\ Düsseldorf, Germany; ${ }^{4}$ Alexianer \\ Krefeld, Maria Hilf Clinic, Krefeld, \\ Germany
}

Background: Oral cholinesterase inhibitors at doses efficacious for the treatment of Alzheimer's disease $(\mathrm{AD})$ are often prematurely discontinued due to gastrointestinal side effects. In controlled clinical trials, transdermal rivastigmine demonstrated less such effects at similar efficacy. The current study aimed to verify the validity of this data in daily practice.

Methods: This was a prospective, multicenter, observational study on transdermal rivastigmine in Germany. Eligible patients were those with $\mathrm{AD}$ who had not yet been treated with rivastigmine. Outcome measures were changes in clock-drawing test, Mini-Mental State Examination (MMSE), Caregiver Burden Scale, Clinical Global Impression (CGI), physicians' assessments of tolerability, and the incidence of adverse events (AEs) over 4 months of treatment.

Results: In 257 centers 1113 patients were enrolled; 614 women and 499 men, mean age 76.5 years. In $58 \%$ of patients $\mathrm{AD}$ was treated for the first time and in $42 \%$ therapy was switched to transdermal rivastigmine, mostly due to lack of tolerability $(13.6 \%)$ or effectiveness $(26.9 \%)$. After 4 months, $67.4 \%$ of patients were on the target dose of $9.5 \mathrm{mg}$ /day and $21.8 \%$ were still on $4.6 \mathrm{mg} /$ day. MMSE significantly improved in patients with and without pretreatment ( $\triangle \mathrm{MMSE}$, $0.9 \pm 3.4$ and $0.8 \pm 3.4$, respectively, both $P<0.001$ ); the CGI score improved in $60.9 \%$ and $61.3 \%$ of patients, respectively. Overall $11.7 \%$ of patients had AEs, mainly affecting the skin or the gastrointestinal tract; in $1.1 \%$ of cases AEs were serious; $14.7 \%$ of patients discontinued therapy, $6.0 \%$ due to AEs. With rivastigmine treatment the percentage of patients taking psychotropic comedication decreased, particularly in first-time treated rivastigmine patients (from $27.1 \%$ to $22.6 \% ; P<0.001$ ).

Conclusion: Results were in line with data from controlled clinical trials. Switching from any other oral acetylcholinesterase inhibitor to transdermal rivastigmine may improve cognition.

Keywords: rivastigmine patch, Alzheimer's disease, treatment practice

\section{Introduction}

In Germany, about one million people suffer from dementia, ${ }^{1,2}$ with $50 \%$ to $70 \%$ of these due to Alzheimer's disease (AD). Based on demographic changes, AD prevalence is predicted to increase by $50 \%$ in the next 25 years. The primary objective of current pharmacological AD therapy is to slow down disease progression and to preserve the capability for activities of daily life. ${ }^{3}$

Cholinesterase (CHE) inhibitors are a mainstay in the treatment of mild to moderate AD. Only oral treatments were available until rivastigmine (Exelon ${ }^{\circledR}$; Novartis, Basel, Switzerland) was approved as the first transdermal antidementia drug in 2007. Transdermal patches provide continuous drug delivery and maintain rivastigmine concentrations within the optimal therapeutic window avoiding the
Correspondence: Stefan Spittler Alexianer Krefeld $\mathrm{GmbH}$, Dießemer Bruch 8I, 47805 Krefeld, Germany Tel +49 2I5I 334770I

Fax +49 21513347708

Email stefan.spittler@alexianer-krefeld.de 
peaks and troughs associated with oral administration. The rivastigmine patch was demonstrated to be as efficacious as the highest oral doses and with approximately three times fewer reports of gastrointestinal adverse events (AEs), such as nausea and vomiting. ${ }^{4}$ Moreover, the once-daily application of the patch is supposed to improve compliance with the recommended dosing regimen. Better compliance may increase effectiveness and reduce caregiver burden, institutionalization rate, and costs. Given these advantages, the rivastigmine patch may be superior to oral CHE inhibitors and may advance the treatment of AD long-term. ${ }^{5}$

However, patients in clinical trials are known not to be representative of the total target population. Selection bias is particularly caused by excluding patients who do not respond to existing first-line treatments. Therefore, the current study aimed to verify the external validity of clinical trial data on the efficacy and tolerability of transdermal rivastigmine under daily routine conditions in Germany. A subgroup analysis was undertaken to elucidate the role of previous and concomitant medication.

\section{Methods}

\section{Study design}

This was a prospective, multicenter, observational study on the effectiveness and tolerability of rivastigmine patch for the treatment of AD in everyday practice in Germany. For each eligible patient, physicians were requested to collect data immediately prior to and about 1 month and 4 months after treatment initiation. The study was conducted from January to October 2008 in compliance with the Declaration of Helsinki and all applicable legal requirements.

\section{Patients}

Outpatients with mild-to-moderate AD in conformity with the specification of the drug label were eligible if they had not previously been treated with rivastigmine. Patients had to be fully capable to contract and to make a decision about participation in the study. All included patients consented to the use of their pseudo-anonymized data.

\section{Treatment}

As this was an observational study there were no protocol instructions on treatment. The provided product information specified to use the $5 \mathrm{~cm}^{2}$ patch corresponding to an initial dose of $4.6 \mathrm{mg}$ rivastigmine per 24 hours for a minimum of 4 weeks first and to change to the $10 \mathrm{~cm}^{2}$ patch corresponding to the recommended effective dose of $9.5 \mathrm{mg}$ rivastigmine per 24 hours as tolerability allows.

\section{Outcome measures}

Effectiveness was evaluated based on (a) the Mini-Mental State Examination (MMSE), a brief 30-point screening instrument for cognitive impairment; (b) the clock-drawing test (CDT) to assess on a 7-point scale visual-spatial construction, visual perception, and abstract conceptualization; (c) the Clinical Global Impression (CGI) of the patient as assessed on a 5-point scale by the attending physician; and (d) the caregivers' quality of life on the Caregiver Burden Scale (CBS), parts A and B. Part A included six statements on the caregiver (maximum 30 points) and part B included seven statements on the caregiver-patient relationship (maximum 35 points). Each statement was to be assessed on a 5-point scale with high scores representing high burden.

In addition, drug safety and tolerability were evaluated based on the monitoring of AEs and the physicians' global tolerability assessment per patient. For an evaluation of treatment practice and compliance, daily doses, dose adjustments, concomitant and previous medications, and premature discontinuation of the rivastigmine patch were recorded.

\section{Data analysis}

Diseases were classified according to the International Classification of Diseases, version 10; medications according to the WHO Drug Dictionary as of March 1st 2007; and AEs according to the Medical Dictionary for Regulatory Activities, version 11.1. All patients who gave informed consent and started treatment with rivastigmine patch based on the recommendation of their physician entered the analysis. Descriptive data analyses were performed using summary statistics for categorical and quantitative data. Continuous data were described as median, means, standard deviation (SD), minimum, maximum, and 25th and 75th percentiles. Stratification and categorization were based on clinical criteria. In case of qualitative variables the absolute and relative frequencies were calculated. In stratified analyses percentages were given per category and stratum. Safety analyses included tabulation of type and frequency of AEs on a patient and event basis. The role of premedication for effectiveness and tolerability was examined by a subgroup analysis comparing outcomes in patients who had previously been treated with other antidementia drugs (pretreated) and patients who received rivastigmine as the first antidementia drug (first-time treated). For inferential statistics a two-sided $t$-test at a significance level of 0.05 was used. All analyses were conducted with SAS for Windows (version 9.1; SAS Institute, Cary, NC). 


\section{Results}

\section{Patient population}

In 257 centers, 1113 patients, 614 women $(55.2 \%)$ and 499 men (44.8\%), with a mean age of $76.5 \pm 7.5$ (SD) years were enrolled; in $12.9 \%$ of patients onset of $\mathrm{AD}$ was categorized as early and in $61.5 \%$ as late; for $18.3 \%$ onset was not specified and $8.8 \%$ of patients had additional diagnoses associated with dementia. Patients were diagnosed with AD on average $1.0 \pm 1.7$ years (mean $\pm \mathrm{SD}$ ) prior to the baseline visit and first dementia symptoms manifested $1.2 \pm 1.9$ years before. About $42 \%$ of patients were included in the pretreated group. The most common previous treatments were other CHE inhibitors (24.5\%). About two thirds (64.2\%) switched to the rivastigmine patch due to lack of efficacy and about one third (32.4\%) due to lack of tolerability. At baseline, first-time treated, and pretreated subgroups were comparable in demographic characteristics, but the disease in pretreated patients was further advanced (Table 1).

\section{Treatment practice and compliance}

The study was completed by $92.8 \%$ of patients. The majority of these patients also attended both follow-up visits; $6.1 \%$ of patients attended one follow-up visit only and $1.1 \%$ of patients were lost to follow up without any post-treatment assessment. Patch treatment was discontinued within the 4 month observation period by $164(14.7 \%)$ patients, on average $91 \pm 43$ days after initiation, due to AEs (6.0\%), lack of compliance (3.1\%) and/or efficacy (1.8\%), for unknown

Table I Demographics and disease characteristics in first-time and pretreated patients

\begin{tabular}{|c|c|c|c|}
\hline & $\begin{array}{l}\text { First-time } \\
\text { treated } \\
n=638\end{array}$ & $\begin{array}{l}\text { Pretreated } \\
n=457\end{array}$ & $P$ \\
\hline Age (years) & 76.7 (7.7) & $76.2(7.2)$ & 0.2536 \\
\hline Sex & & & 0.6250 \\
\hline - Male & $44.1 \%$ & $45.7 \%$ & \\
\hline - Female & $55.9 \%$ & $54.3 \%$ & \\
\hline$A D$ due to ICD 10 & & & 0.1345 \\
\hline - Early onset AD & $12.7 \%$ & $13.3 \%$ & \\
\hline - Late onset AD & $59.3 \%$ & $64.8 \%$ & \\
\hline - AD NOS & $20.0 \%$ & $16.1 \%$ & \\
\hline - Other & $8.0 \%$ & $5.8 \%$ & \\
\hline \multicolumn{4}{|l|}{ Disease history (years) } \\
\hline - $\mathrm{AD}$ & $0.6(I .5)$ & I.5 (I.9) & $<0.0001$ \\
\hline - Dementia & $0.7(1.6)$ & $\mathrm{I} .7(2.1)$ & $<0.0001$ \\
\hline Housing conditions & & & $<0.000$ I \\
\hline - Solitarily & $16.3 \%$ & $9.4 \%$ & \\
\hline - With family & $67.6 \%$ & $79.4 \%$ & \\
\hline - Homebound/assisted living & $16.1 \%$ & $1 \mathrm{I} .2 \%$ & \\
\hline
\end{tabular}

Abbreviations: AD, Alzheimer's disease; ICD I0, International Classification of Diseases, version I0; NOS, not otherwise specified.
(3.3\%) or other reasons $(3.0 \%)$. In compliance with the product information, $95.6 \%$ of patients started treatment at the recommended initial dose of $4.6 \mathrm{mg} / 24$ hours (Figure 1). In $62.3 \%$ of patients the dose was subsequently escalated to $9.5 \mathrm{mg} / 24$ hours. In about one quarter of patients, the dose was not changed at all and $21.8 \%$ of patients remained on the low initial dose for the 4 month study period. For a minority of patients $(2.7 \%)$ the dose was adjusted twice or decreased once.

At the initial visit, $29.0 \%$ of patients received comedication, most commonly antipsychotics (17.1\%) and antidepressants (12.3\%). The most frequently recorded antipsychotic drugs accounting for $86.3 \%$ of this drug class were risperidone, melperone, quetiapine, and pipamperone. Citalopram, mirtazapine, sertraline, and venlafaxine together accounted for $71.5 \%$ of all antidepressants given concomitantly. Within 4 months on transdermal rivastigmine, the proportion of patients taking psychotropic comedication overall decreased from $29.0 \%$ to $25.8 \%$ with $15.4 \%$ taking antipsychotics and $11 \%$ antidepressants; among these drug classes, greatest decreases showed pipamperone from $11.1 \%$ to $9.4 \%$ of patients and sertraline from $10.2 \%$ to $6.6 \%$ of patients, respectively.

\section{Effectiveness}

Patients showed no deterioration in disease-specific outcome measures. Between baseline and the end of the observation period (4 months), mean scores on the MMSE and the CDT significantly increased by $0.9 \pm 3.4$ (from $18.1 \pm 5.7$ to $18.8 \pm 5.9 ; P<0.0001$ ) and $0.3 \pm 1.5$ (from $3.2 \pm 2.0$ to $3.5 \pm 2.2 ; P<0.0001)$, respectively. After 1 month, the attending physician rated the CGI in $50.9 \%$ of patients as better, in $45.6 \%$ as unchanged, and in $0.4 \%$ as worse (3.1\% missing). After 4 months, the corresponding rates were $61.1 \%, 28.9 \%$, and $3.1 \%$, respectively ( $6.8 \%$ missing) (Figure 2). The mean CBS-A and -B scores significantly decreased by $0.9 \pm 3.4$ (from initially $18.4 \pm 6.1$ to $17.3 \pm 5.9$ after 4 months; $P<0.0001$ ) and $1.2 \pm 3.4$ (from initially $15.8 \pm 6.5$ to $15.2 \pm 6.1 ; P<0.0001)$, respectively.

\section{Tolerability and safety}

After 1 month of treatment, physicians rated tolerability as very good or good in $93.7 \%$ of patients and poor in $2.8 \%$ of patients (3.5\% unknown or missing). After 4 months, it was still good or very good in $86.6 \%$ of patients and poor in $5.9 \%$ of patients (7.6\% unknown or missing) (Figure 3).

A total of $226 \mathrm{AEs}$ were reported in 130 (11.7\%) patients; of these, physicians deemed 166 at least possibly related to 


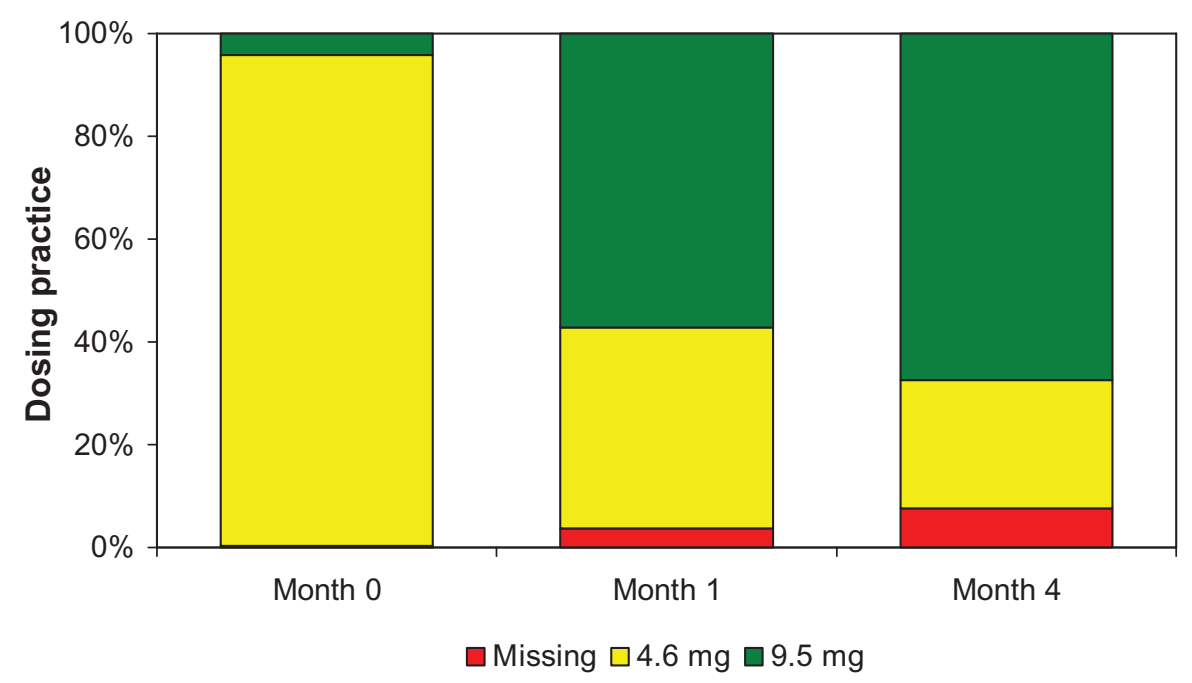

Figure I Dosing practice at baseline, after I month, and after 4 months.

rivastigmine, 26 of them being serious. Potentially related AEs occurred in 104 patients (9.4\%): 58 patients (5.2\%) had one; 32 patients $(2.9 \%)$ two; ten patients $(0.9 \%)$ three; three patients $(0.3 \%)$ four; and one patient $(0.1 \%)$ five such AEs.

The most frequent AEs were erythema and nausea, and the most frequently affected system organ classes were skin and subcutaneous tissue disorders, gastrointestinal, psychiatric, and nervous system disorders (Table 2). More than half of the skin and subcutaneous tissue disorders occurred within the first 6 weeks of treatment. Psychiatric and nervous system disorders were less frequent than dermatological and gastrointestinal disorders, but these AEs were more often serious. Overall incidence rates of potentially rivastigmine-related
AEs and serious AEs (SAEs) were $8.3 \%$ and $1.1 \%$ of patients, respectively. Severity was mild in $29.0 \%$, moderate in $39.6 \%$, and severe in $20.1 \%$ of AEs (11.2\% missing). By the end of the study, patients had recovered from $72 \%$ and $61.6 \%$ of such AEs and SAEs, respectively, whereas $18.9 \%$ of AEs and $11.5 \%$ of SAEs in a total of 19 patients had not resolved yet. One fatal SAE was deemed probably drug-related by the investigator, a completed suicide after hallucination of a 93-year-old female patient, 49 days after treatment initiation.

\section{Role of premedication}

Pretreated as compared to first-time treated patients tended to escalate earlier to the target dose (after 1 month 61.2\%

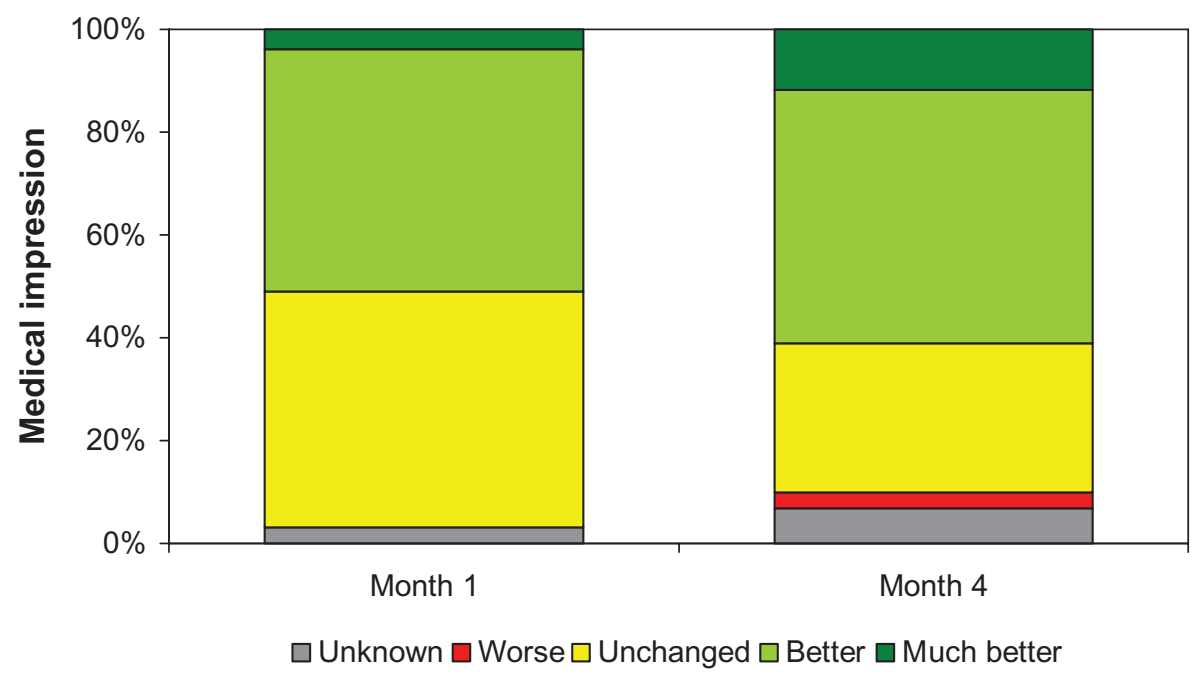

Figure 2 Overall medical impression of the patient as assessed by the attending physician after I month and after 4 months. 


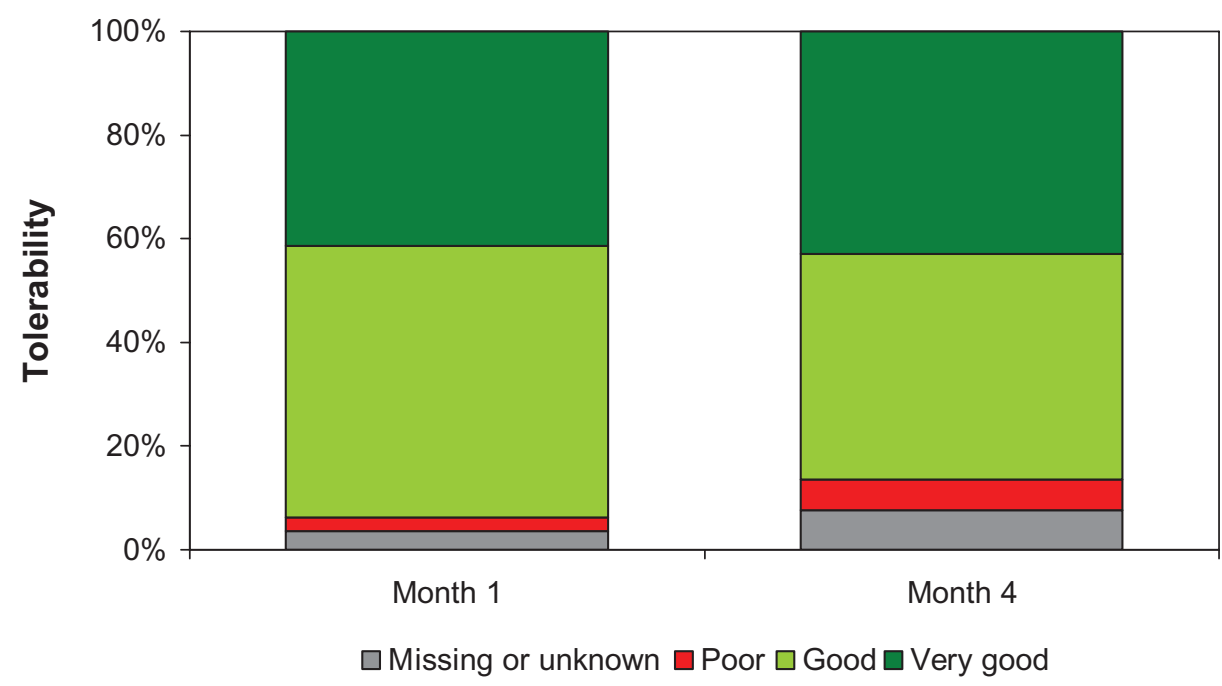

Figure 3 Tolerability as assessed by the attending physician after I month and after 4 months.

Table 2 Incidence of AEs and SAEs (by system organ class and preferred term) that physicians deemed at least possibly related to rivastigmine, (preferred terms listed only if total incidence $\geq 0.5 \%$ )

\begin{tabular}{|c|c|c|c|c|c|c|}
\hline & \multicolumn{2}{|l|}{$\mathbf{A E}$} & \multicolumn{2}{|l|}{ SAE } & \multicolumn{2}{|c|}{ Total } \\
\hline & $\mathbf{n}$ & $\%$ & $\mathbf{n}$ & $\%$ & $\mathbf{n}$ & $\%$ \\
\hline \multicolumn{7}{|l|}{ MedDRA system organ class } \\
\hline - preferred term & & & & & & \\
\hline Total & 1113 & 100 & 1113 & 100 & 1113 & 100 \\
\hline $\begin{array}{l}\text { Skin and subcutaneous } \\
\text { tissue disorders }\end{array}$ & 65 & 5.8 & - & - & 65 & 5.8 \\
\hline - Dermatitis contact & 10 & 0.9 & - & - & 10 & 0.9 \\
\hline - Erythema & 28 & 2.5 & - & - & 28 & 2.5 \\
\hline - Pruritus & 10 & 0.9 & - & - & 10 & 0.9 \\
\hline Gastrointestinal disorders & 34 & 3.1 & I & 0.1 & 35 & 3.1 \\
\hline - Nausea & 19 & 1.7 & - & - & 19 & 1.7 \\
\hline - Vomiting & 10 & 0.9 & - & - & 10 & 0.9 \\
\hline Psychiatric disorders & 19 & 1.7 & 13 & 1.2 & 32 & 2.9 \\
\hline - Restlessness & 7 & 0.6 & I & 0.1 & 8 & 0.7 \\
\hline Nervous system disorders & 10 & 0.9 & 4 & 0.4 & 14 & 1.3 \\
\hline - Dizziness & 8 & 0.7 & 1 & 0.1 & 9 & 0.8 \\
\hline $\begin{array}{l}\text { General disorders and } \\
\text { administration site conditions }\end{array}$ & 7 & 0.6 & 2 & 0.2 & 9 & 0.8 \\
\hline Cardiac disorders & 1 & 0.1 & 2 & 0.2 & 3 & 0.3 \\
\hline $\begin{array}{l}\text { Metabolism and nutrition } \\
\text { disorders }\end{array}$ & - & - & 2 & 0.2 & 2 & 0.2 \\
\hline $\begin{array}{l}\text { Injury, poisoning, } \\
\text { and procedural complications }\end{array}$ & - & - & I & 0.1 & 1 & 0.1 \\
\hline Renal and urinary disorders & - & - & I & 0.1 & 1 & 0.1 \\
\hline Ear and labyrinth disorders & I & 0.1 & 0 & 0 & I & 0.1 \\
\hline Immune system disorders & I & 0.1 & - & - & I & 0.1 \\
\hline Investigations & I & 0.1 & - & - & I & 0.1 \\
\hline $\begin{array}{l}\text { Respiratory, thoracic, and } \\
\text { mediastinal disorders }\end{array}$ & 1 & 0.1 & - & - & 1 & 0.1 \\
\hline Total & 140 & 12.6 & 26 & 2.3 & 166 & 14.9 \\
\hline
\end{tabular}

Abbreviations: AE, adverse event; SAE, serious adverse event; MedDRA, Medical Dictionary for Regulatory Activities. versus $54.5 \%$ on $9.5 \mathrm{mg} /$ day), to remain longer in the trial (drop-out rates after 4 months, $5.6 \%$ versus $9.0 \%$ ), and a higher proportion was on the target dose after 4 months (71.0\% versus $64.9 \%$ ), although none of these differences was actually significant. The decrease in the proportion of patients taking psychotropic comedication was more pronounced and significant in patients who had not been pretreated (from $27.1 \%$ to $22.6 \% ; P<0.001$ ). MMSE and the CGI improved under rivastigmine, regardless of whether patients were pre- or first-time treated. Over 4 months, the MMSE changed by $0.8 \pm 3.4$ in pretreated and by $0.9 \pm 3.4$ in first-time treated patients; the CGI improved in $61.3 \%$ and $60.9 \%$, respectively (all $P>0.1$ ).

\section{Discussion}

Rivastigmine was the first CHE inhibitor of which a patch formulation was approved for the treatment of mild to moderate AD. ${ }^{4,6}$ According to results from a double-blind, randomized, active- and placebo-controlled clinical trial, the Investigation of transDermal Exelon in ALzheimer's disease (IDEAL), transdermal rivastigmine provides superior tolerability at noninferior efficacy as compared to the capsule formulation. Through improved patients' compliance and adherence this may increase drug effectiveness. However, clinical trial data need to be verified in daily practice as external validity might be limited, in particular due to selection bias caused by inclusion and exclusion criteria.

In the IDEAL trial inclusion criteria were 50 to 85 years of age, an MRI-confirmed AD diagnosis not older than 1 year 
prior to inclusion, MMSE baseline scores between 10 and 20, and patients had to live with someone in the community or to be in daily contact with a caregiver. Exclusion criteria were advanced, severe, progressive, or unstable disease, an unconfirmed $\mathrm{AD}$ diagnosis, or another $\mathrm{AD}$ treatment within 4 weeks prior to randomization. ${ }^{4,6}$ Not all of these data were collected in the current study, but solely based on the age and MMSE criteria about $64 \%$ of the patient population although similar in size and likely representative of the total target population in Germany - would have been excluded. This is much higher than one might expect from the overall screening failure rate of $18.4 \%$ in IDEAL if both populations were the same. Consequently, the patch-treated patients in this study were slightly older $(76.5 \pm 7.5$ years versus $73.6 \pm 7.9$ years), significantly more often male (44.8\% versus $32.0 \%)$, and had lower MMSE baseline scores $(18.1 \pm 5.7$ versus $16.5 \pm 3.0)$.

However, despite those differences in patient populations, effectiveness shown in this trial was well in line with corresponding results of IDEAL: MMSE scores significantly increased on average by 0.7 ( 0.9 in the first-time treated group) over 4 months versus 0.9 in the corresponding treatment arm of IDEAL. ${ }^{4,6}$ CDT scores increased in both studies by 0.3 . Percentages of patients with improved CGI treated with transdermal rivastigmine were higher in the current study but this comparison is biased as the assessment method was different. CBS was not used in IDEAL, however decreasing scores in both Parts A and B in this study are in line with the distinct caregiver preference for the patch relative to capsules observed in IDEAL. ${ }^{7}$

In the current study, safety and tolerability of transdermal rivastigmine appeared even more favorable; however this has to be taken with caution. The lower discontinuation rate of $14.7 \%$ versus $21.8 \%$ in IDEAL might be due to the 2 months shorter treatment duration and the less rigid dose escalation to $9.5 \mathrm{mg}$ /day after the first month. Actually, under routine conditions about one fifth of patients still remained on the initial dose of $4.6 \mathrm{mg} /$ day over 4 months. By contrast, the difference in the percentage of patients discontinuing due to an $\mathrm{AE}(6.0 \%$ versus $9.6 \%)$ is quite small. However, one has to bear in mind that the AE monitoring in a GCPcompliant clinical trial is much closer and not comparable to that of the current observational study. This is clearly reflected by recording only $12 \%$ of patients having any AE whereas in the corresponding treatment arm of IDEAL $51 \%$ of patients had any AE. In IDEAL, the most common AEs were nausea (7.2\%) and vomiting (6.2\%), whereas the incidence of severe skin irritation was stated to be less than
10\%. Apart from these administration site reactions, which were an endpoint rather than an AE in IDEAL, nausea and vomiting were also the most frequently observed single AEs in common practice.

Our results are also in line with those of several open-label studies demonstrating benefits from switching AD therapy to rivastigmine after other $\mathrm{CHE}$ inhibitors and particularly donepezil have failed in terms of efficacy or tolerability. ${ }^{8,9}$ An additional and rather specific benefit associated with the use of rivastigmine might be the reduction of psychotropic comedication. This may be a result of increased cholinergic function in the human limbic system and thalamus due to the inhibition of both acetylcholinesterase and butyrylcholinesterase by rivastigmine. The dual inhibition may contribute to a drug-saving effect as butyrylcholinesterase activity increases with AD progression and severity. Such a drug saving effect was first described in another observational study (EXALAN) using oral rivastigmine in a similar population and over a similar period of time. ${ }^{10}$ In the current study, such a drug-sparing effect was also detectable with the transdermal formulation, although it was less striking. However, the effect sizes observed in both studies are not directly comparable as in the current study neither patients had to take any psychoactive medication for inclusion (as in EXALAN) nor were dose reductions recorded. In EXALAN, patients reducing psychotropic medication were shown to also gain the largest cognitive benefit from rivastigmine. Based on the small sample size, this could not be examined in the current study, but the proportion of patients who discontinued psychotropic comedication as well as the clinical benefit tended both to be higher in first-time treated as compared to pretreated patients. Whether such a drug sparing effect is indeed related to premedication or to different disease characteristics in both subgroups remains to be elucidated.

\section{Conclusion}

In conclusion, our study confirmed the tolerability and effectiveness of transdermal rivastigmine in daily practice. Interestingly, the number of adverse events and the magnitude of cognitive improvement were similar in first- and pretreated patients and among subgroups of the latter. This further supports consideration of transdermal rivastigmine when other treatments have failed due to lack of either efficacy or tolerability. Whether rivastigmine has a direct drug-sparing effect on psychotropic comedication as seen in this and another observational study deserves further investigation in controlled clinical trials. 


\section{Acknowledgment}

We thank all investigators for enrolling patients, Klaus Hechenbichler for statistical support, and Uwe Totzke for editorial support.

\section{Disclosure}

JS and SS report no conflicts of interest in this work. FT and KA are employees of Novartis, the manufacturer of the tested drug.

\section{References}

1. Bickel H. Dementia syndrome and Alzheimer disease: an assessment of morbidity and annual incidence in Germany. Gesundheitswesen. 2000; 62(4):211-218.

2. Ziegler U, Doblhammer G. Prevalence and incidence of dementia in Germany - a study based on data from the public sick funds in 2002 . Gesundheitswesen. 2009;71(5):281-290.

3. Hort J, O'Brien JT, Gainotti G, et al. EFNS guidelines for the diagnosis and management of Alzheimer's disease. Eur J Neurol. 2010;17(10): 1236-1248.
4. Winblad B, Grossberg G, Frolich L, et al. IDEAL: a 6-month, doubleblind, placebo-controlled study of the first skin patch for Alzheimer disease. Neurol. 2007;69(4 Suppl 1):S14-S22.

5. Wentrup A, Oertel WH, Dodel R. Once-daily transdermal rivastigmine in the treatment of Alzheimer's disease. Drug Des Devel Ther. 2009;2: 245-254.

6. Winblad B, Cummings J, Andreasen N, et al. A six-month doubleblind, randomized, placebo-controlled study of a transdermal patch in Alzheimer's disease - rivastigmine patch versus capsule. Int J Geriatr Psychiatry. 2007;22(5):456-467.

7. Winblad B, Kawata AK, Beusterien KM, et al. Caregiver preference for rivastigmine patch relative to capsules for treatment of probable Alzheimer's disease. Int J Geriatr Psychiatry. 2007;22(5):485-491.

8. Emre M. Switching cholinesterase inhibitors in patients with Alzheimer's disease. Int J Clin Pract Suppl. 2002;(127):64-72.

9. Gauthier S, Emre M, Farlow MR, Bullock R, Grossberg GT, Potkin SG Strategies for continued successful treatment of Alzheimer's disease: switching cholinesterase inhibitors. Curr Med Res Opin. 2003;19(8): 707-714.

10. Verny M, Fremont P, Bourrin JC, Bourdeix I, Pere JJ. Reduced psychotropic drug use in patients with Alzheimer's disease receiving rivastigmine: results of the EXELAN study. J Drug Assess. 2004; 7: $123-132$.
Neuropsychiatric Disease and Treatment

\section{Publish your work in this journal}

Neuropsychiatric Disease and Treatment is an international, peerreviewed journal of clinical therapeutics and pharmacology focusing on concise rapid reporting of clinical or pre-clinical studies on a range of neuropsychiatric and neurological disorders. This journal is indexed on PubMed Central, the 'PsycINFO' database and CAS.

\section{Dovepress}

The manuscript management system is completely online and includes a very quick and fair peer-review system, which is all easy to use. Visit http://www.dovepress.com/testimonials.php to read real quotes from published authors. 